\title{
Dose Adjustment for Normal Eating: Longer Term Perspectives of Adults with Type 1 Diabetes
}

\author{
Pat Rapley1*, Stephanie Axon², Gwen Babel2, Krystina Creighton², Joey M. Kaye², \\ Suzanne Brown ${ }^{2}$ \\ ${ }^{1}$ Centre for Nursing Research, Sir Charles Gairdner Hospital, Perth, Australia \\ ${ }^{2}$ Department of Endocrinology and Diabetes, Sir Charles Gairdner Hospital, Perth, Australia \\ Email: *pat.rapley@health.wa.gov.au, stephanie.Axon@health.wa.gov, gwen.babel@health.wa.gov.au, \\ creighton.krystyna@health.wa.gov.au, joey.kaye@health.wa.gov, suzanne.Brown@health.wa.gov
}

Received 13 May 2014; revised 8 June 2014; accepted 3 July 2014

Copyright (C) 2014 by authors and Scientific Research Publishing Inc.

This work is licensed under the Creative Commons Attribution International License (CC BY). http://creativecommons.org/licenses/by/4.0/

(c) (7) Open Access

\section{Abstract}

Aim: To explore the longer term blood glucose self-monitoring outcomes and frequency of monitoring for outpatients with diabetes type 1 after completion of the Dose Adjustment for Normal Eating (DAFNE) course. The hypothesis was that DAFNE outcomes would differ according to frequency of glucose monitoring. Methods: A sequential data-triangulation design using existing baseline $\left(T_{0}\right)$ and 12-months $\left(T_{12}\right)$ DAFNE course data and interview data from 12 randomly selected participants who had completed the course two years ago. Results: Age range was 23 to 70 years with HbA1c $6.1 \%$ to $12.6 \%$ at $\mathrm{T}_{0}$ and $6.1 \%$ to $11.4 \%$ at $\mathrm{T}_{12}$. Comparisons of HbA1c, PAID, HAD subscales anxiety and depression, and covariate data between $T_{0}$ and $T_{12}$ indicatedsignificant reductions in the mean depression and PAID scores (both $P<0.001$ ) for the whole group. For the two groups who recorded their blood glucose less than three times or three or more times per day, changes were not significantly different. For both groups, the trend between $T_{0}$ and $T_{12}$ was downwards for change in mean blood glucose level and all survey scales. The proportion of all participants with $\mathrm{T}_{12} \mathrm{HbA1c}$ at or below their $\mathrm{T}_{0}$ value was greater than $50 \%$ (Proportion $=69 \%$, 95\% CI: $56 \%-79 \%)$ but only the highest HbA1c tertile group showed a significant difference $(P=$ 0.003). There was an average decrease in the incidence of hypoglycaemic events of 0.6 overall: The greatest change was for the high HbA1c tertile with a mean decrease of 0.8 . The interview data suggested that DAFNE graduates experimented more with food, exercise, and insulin; gained knowledge; learnt personal body needs; increased awareness of blood glucose level; gained confidence and improved their quality of life. Conclusions: There was insufficient evidence to conclude that frequency of blood glucose monitoring influenced metabolic control. However, people

${ }^{*}$ Corresponding author.

How to cite this paper: Rapley, P., Axon, S., Babel, G., Creighton, K., Kaye, J.M. and Brown, S. (2014) Dose Adjustment for Normal Eating: Longer Term Perspectives of Adults with Type 1 Diabetes. Journal of Diabetes Mellitus, 4, 179-188.

http://dx.doi.org/10.4236/jdm.2014.43026 
with type 1 diabetes who undertake the less restricted DAFNE approach to diabetes self-management can improve their quality of life and glycaemic control.

\title{
Keywords
}

\author{
DAFNE, Adults, Type 1 Diabetes, Long Term
}

\section{Background}

Two simple facts underlie this paper. First, individuals with diabetes are responsible for $95 \%$ of their own diabetes management [1]. Second, self-report costs for people with type 1 diabetes-but without complicationsindicate health care costs contribute over $90 \%$ of the direct costs and half of this is hospital-related [2]. Hence, the development of effective self-monitoring of blood glucose (SMBG) behaviours is basic to reducing health care costs linked to diabetes-related hospitalization [3] and or hospital emergency presentations.

In addition to the problem of costs, educational programs must do more than focus on diabetes knowledge [1] [4] [5]. Education processes need to acknowledge the juxtaposition between essential and unrelenting blood glucose management and an individual's desire to make spontaneous food choices. Education to improve diabetes task-specific efficacy can positively impact behaviour change [5]-[7]. For example, the Dose Adjustment for Normal Eating (DAFNE) program is an educational intervention that can pay for itself over four to five years through improvements in people's glycaemic control and reduced diabetes complication rates [8]. It has also demonstrated improvement in participants' quality of life [9]-[11]. The DAFNE motto is "Like what you eateat what you like"-facilitated by a focus on flexibility through information that can enable individuals to avoid hyperglycaemic and debilitating hypoglycaemic events.

DAFNE participants learn to "...think of blood glucose and HbA1c as indicators that continually change in response to many controllable and uncontrollable factors..." [12]. Recording a blood glucose (BG) level and insulin dose before meals and bed-time provides the opportunity to interpret and identify BG level patterns, enabling a considered response to a lower or higher than target BG level. The knowledge and skill required to do this is part of the DAFNE program. The one-week skills-based outpatient course sits within a 12-month program. It is a client-centred program that focuses on diabetes management with carbohydrate counting at its core. That is, insulin replacement as needed and not dietary manipulation to fit prescribed insulin dosehence the potential for greater dietary freedom. Over time participants' sense of control over their diabetes as well as their confidence in decisions related to diabetes self-management increases [9]. Specifically, readiness for positive behaviour change is more likely to improve when knowledge [13] and diabetes-related confidence increases [6] [14].

The increase in diabetes-related confidence can be explained by Self-Efficacy Theory [15] and its four sources of efficacy information advocated for behaviour change [16]-[18]. Secondly, the DAFNE program includes the therapeutic effects of groups. Group dynamics and processes in a workshop may have greater potential to change habitual or established praxis than one-to-one teaching [5] [19].

Whilst there is a direct association between SMBG frequency and glucose control in type 1 diabetes (T1D), [20] [21] difficulty with interpretation and appropriate action may also account for the lack of consistent evidence around self-monitoring efficacy [22]. A phenomenological study [23] suggested that one of the most difficult self-care behaviours was the checking and recording of blood glucose(BG) four times per day with a view to keeping it within certain limits. Yet without knowledge of how to interpret results a greater barrier to metabolic control arises. In order to keep BG within certain limits DAFNE also teaches participants how to record all BG data, to interpret, and then to adjust their insulin accordingly.

Knowing how to interpret BG results and knowing what to do may reduce psychological distresses in general or diabetes-specific emotional distress; together they make up the quality of life belief that in turn influences metabolic control [24]. DAFNE studies have found a high prevalence of psychological distress in patients with type 1 diabetes prior to DAFNE training [25] [26]. Substantial improvements in anxiety, depression and perceived health were seen at follow up [25] [27], particularly amongst subjects with evidence of significant anxiety and depression in the Hopkins et al.'s study. 
Whilst DAFNE participants are expected to monitor and record blood glucose four times per day, anecdotal feedback from earlier course participants was consistent with the extant research literature: That BG self-monitoring in adults with diabetes type 1, though essential, was uncommon [28]. Studies have not explored whether the same DAFNE outcomes can be achieved whilst monitoring less often.

The aim of this study was to explore the long term SMBG outcomes and frequency of monitoring for outpatients with diabetes type 1 after completion of the Dose Adjustment for Normal Eating (DAFNE) course. The hypothesis was that DAFNE outcomes would differ according to frequency of glucose monitoring.

\section{Methods}

A sequential data triangulation design using existing pre and post DAFNE course data $(\mathrm{N}=85)$, and interview data collected from 12 randomly selected participants who had completed the DAFNE course at least two years ago.

\subsection{Sample}

The study target group included 85 adult Western Australian course participants on the OZ DAFNE (Australian or National DAFNE) consortium's database. Existing DAFNE data were imported from the on-line environment.

\subsection{Recruitment}

The initial DAFNE course inclusion criteria were: Adults with type 1 diabetes for more than one year, prepared to monitor and record blood glucose four times per day, attend five consecutive days of the course, prepared to meet for a two-hour follow-up workshop five to six weeks after the course, and to have an individual interview a year later. Exclusion criteria were: Not in diabetes "honeymoon" phase, not using an insulin pump, and no end-stage diabetes-related complications. These initial DAFNE course participants had been informed that their de-identified data would be entered into a national data base.

In this study, individuals who had completed the DAFNE course between 2005 and 2008 were contacted by the Diabetes Centre staff. The 12 interview volunteers were obtained using a computer-generated list of random numbers whereby 24 of the 85 participants who completed the DAFNE course more than two years ago were sent invitation letters that explained the study and commitments, the interview format and a request to return the enclosed consent form: 12 replies were received. Confidentiality was ensured by the removal of identifying details from the interview during transcription.

\subsection{Data Collection}

Existing quantitative data were collected from the OZ-DAFNE consortium's database for baseline $\left(\mathrm{T}_{0}\right)$ and 12 month data $\left(\mathrm{T}_{12}\right)$. Background variables of relevance for this study included age, gender, body mass index, lipids, blood pressure, monitoring / recording history, and history of hypoglycaemic episodes since last annual DAFNE review. Hypoglycaemia was defined as, “...a hypoglycaemic episode you were unable to treat yourself”. Data also included scores from two validated questionnaires - the Hospital Anxiety and Depression Scale (HADS) [29] and the Problem Areas in Diabetes (PAID) [30]. The additional data for this study included 12 open-ended interview questions focused on the person's dietary experiences and perception of their health and quality of life since completing the DAFNE course. They were conducted by a registered nurse cognisant of the aim of the DAFNE course.

\subsection{Ethics}

The ethical approval for this study was given by Sir Charles Gairdner Hospital’s Human Research Ethics Committee.

\subsection{Analysis}

Statistical analyses were carried out in SPSS (version 18) and the R Statistical Computing Environment (R version 3.0.1) [31]. Power calculations were completed with $G^{*}$ Power 3.0.5 software [32]. Statistical significance 
was set at 5\%. The sample size required for the study was calculated in the context of repeated measures ANOVA, with an interest in detecting a clinically significant mean difference of $1.2 \%$ in glycated haemoglobin (HbA1c) between groups, and assuming correlation of 0.8 between repeated measures, a common within groups SD of $1.6 \%, 80 \%$ minimum power and 5\% type I error. Cronbach's alpha was used to test the internal reliability of instruments, with reliability analyses set to pair-wise deletion of missing data. Descriptive statistics are given as mean (SD) for continuous variables and counts (\%) for categorical variables.

Participants were classified into two groups according to the frequency of monitoring in the two weeks prior to the $\mathrm{T}_{12}$ survey: Groups $\mathrm{A}$ and $\mathrm{B}$ - those who purported to monitor at least three times daily or who monitored less than three times a day respectively. Participants were further classified into tertiles of baseline HbA1c, and the incidence of hypoglycaemic events compared across tertiles at $T_{0}$ to $T_{12}$. The mean change in incidence of hypoglycaemic events between the beginning and end of the study was also assessed.

Distributions of the variables of interest were compared between groups using the independent or paired samples t-test, as appropriate. Where data were from a skewed distribution, a transformation was applied. The $x^{2}$ test was used to compare proportions across groups. Comparisons of HbA1C and the HADS and PAID survey responses were made firstly between $T_{0}$ and $T_{12}$ for the whole cohort. Secondly groups $A$ and $B$ were compared at each time point for the same responses. Repeated measures ANOVA was then used to compare the mean change in HbA1C, HADS and PAID from $T_{0}$ to $T_{12}$ between groups $A$ and $B$, with adjustment for age and gender.

Qualitative data analysis was undertaken to elicit the 12 participant's perception of how the DAFNE course impacted on their life and diabetes. Participants consented to be interviewed and for the conversation to be audio-taped and transcribed for data analysis. All participants were asked the same questions. These were: What impact has DAFNE had on the way you manage your diabetes on a day to day basis? Since the course, has there been a change in your hypos frequency, severity or how you manage them? Has DAFNE changed the way that you eat and if so, how? Has your physical health or wellbeing changed? Has doing the course had an effect on your life style in general or your quality of life? Has the course had any effect on your family or your relationship with family members? Has your social life or entertaining changed? Has the way you manage sport or exercise changed since the DAFNE course? Do you have any other comments to make about the impact of the DAFNE course?

\subsection{Instruments}

The one-page four-point, 14-item, self-report HADS [29] items are based on the psychic or mental symptoms of anxiety and depression rather than emotional and physical disorders. Scores for each item range from zero to three with total scores for both seven-item subscales greater than 11 out of 21 equating to increased anxiety or depression. The self-report Problem Areas in Diabetes (PAID) is a measure of diabetes-specific emotional distress [30]. It is a 20 item, five-point Likert-scale that covers a range of emotional states frequently reported in type 1 and type 2 diabetes. Scores reflect the degree to which the diabetes-related item is perceived as being problematic $(0=$ no problem to $4=$ serious problem). Total score range is zero to 80 with higher scores indicating greater emotional distress. "The 0 - 100 total score is achieved by summing the $0-4$ responses...and multiplying this sum by 1.25 ” [33].

\section{Results}

Power calculations indicated that a total sample size of at least 52 was sufficient to detect a clinically significant difference of $1.2 \%$ in HbA1c with minimum $80 \%$ power and 5\% Type I error, assuming a 1.6 within groups standard deviation. The final sample of 62 - 64 participants was sufficient.

\subsection{Study Population and Instrument Results}

Of the target group of 85, 64 participants with complete HbA1c and survey data were available for analysis. One had missing data at $\mathrm{T}_{0}$ and 20 lacked follow-up $\mathrm{T}_{12}$; they were excluded. Participants' characteristics at baseline $\left(\mathrm{T}_{0}\right)$ are displayed in Table 1. No significant differences were found between the 21 individuals excluded and the 64 participants in the analyzed group. The PAID score was somewhat higher in the excluded compared to the analyzed group, but the difference was not significant (mean (SD)): 36.3 (21.2) vs 28.3 (18.0), $P=0.098$ ). 
Table 1. Summary statistics for the excluded and analysed groups at $\mathrm{T}_{0}$.

\begin{tabular}{ccccc}
\hline Variables & All & Excluded & Analyzed & $P$-value \\
\hline $\mathrm{n}$ & 84 & 20 & 64 & 0.264 \\
Males $(\%)$ & $32(38 \%)$ & $5(25 \%)$ & $27(42 \%)$ & 0.150 \\
Age & $45.8(12.4)$ & $42.3(12.4)$ & $46.8(12.4)$ & 0.950 \\
HbA1c & $8.3(1.3)$ & $8.3(1.3)$ & $8.3(1.3)$ & 0.222 \\
Anxiety & $6.3(4.1)$ & $7.3(5.0)$ & $6.0(3.7)$ & 0.522 \\
Depression & $4.6(3.83)$ & $5.1(4.1)$ & $28.4(3.7)$ & 0.098 \\
PAID & $30.2(19.0)$ & $36.3(21.2)$ & $26.9(5.8)$ & 0.271 \\
BMI & $26.6(5.3)$ & $25.4(3.4)$ & $4.6(1.0)$ & 0.451 \\
Cholesterol & $4.7(1.0)$ & $4.8(1.0)$ & $1.7(0.7)$ & 0.623 \\
HDL & $1.7(0.7)$ & $1.8(0.7)$ & $81.5(19.5)$ & $0.7)$ \\
Triglycerides & $1.0(0.7)$ & $1.2(0.7)$ & $124(14.3)$ & 0.315 \\
Creatinine & $81.3(18.5)$ & $80.6(15.0)$ & $73.3(10.7)$ & 0.456 \\
SBP & $123(14.7)$ & $121(16.0)$ & $74.1(8.6)$ & 0.757 \\
DBP & $73.5(10.2)$ & 0.595 & \\
\hline
\end{tabular}

Key: Count (\%) is given for gender and mean, (standard deviation) for other variables. $P$-values are from t-tests and the Chi-squared test as appropriate. BMI—body mass index, SBP—systolic blood pressure, DBP—diastolic blood pressure.

The age range for the 64 participants was 23 to 70 years (mean 46.8, SD 12.4) with HbA1c of 6.1 to 12.6 at $\mathrm{T}_{0}$ (mean 8.3, SD 1.3) and 6.1 to 11.4 at $\mathrm{T}_{12}$. Comparisons of HbA1c, PAID, HAD subscales anxiety and depression, and covariate data between $\mathrm{T}_{0}$ and $\mathrm{T}_{12}$ indicatedsignificant reductions in the mean of the depression and PAID scores (depression: -1.3 ; PAID: -8.6 ; both $P<0.001$ ) at $\mathrm{T}_{12}$. See Table 2 . More than $75 \%$ of participants scored at or below their $\mathrm{T}_{0}$ value at $\mathrm{T}_{12}$ on the depression and PAID surveys. The evidence for a mean reduction in $\mathrm{HbA1c}$ and anxiety scores was only borderline (HbA1c: $-0.2, P=0.054$; anxiety: $-0.6, P=0.061$ respectively).

Though the change in HbA1c for total sample was only border-line significant, a Wilcoxon paired sample test of tertile subgroups indicated a significant difference for the highest HbA1c tertile group $(P=0.003)$. Nevertheless, the proportion of participants with $\mathrm{T}_{12} \mathrm{HbA1c}$ at or below their $\mathrm{T}_{0}$ value was greater than $50 \%$ (Proportion $=69 \%$, 95\% CI: 56\% - 79\%). The result for the anxiety scale was the same. HbA1c was the most highly correlated of the responses $(P=0.56)$ and PAID the least correlated $(P=0.38)$ between $\mathrm{T}_{0}$ and $\mathrm{T}_{12}$. All correlations were significantly different from zero $(P<0.0001)$. Comparisons of other covariates such as BMI, lipids and blood pressure showed no significant differences between $\mathrm{T}_{0}$ and $\mathrm{T}_{12}$. Although total cholesterol indicated a downward trend this was found to be due to the influence of a single observation.

In accordance with study aim, two groups of data were created to explore DAFNE outcomes when participants recorded less than the recommended rate. The 19 participants who recorded their blood glucose three or more times per day, group A, and the 43 who recorded less than three times a day, group B, were compared. Neither on entry to nor at completion of the study were the two groups significantly different for mean HbA1c, PAID, Anxiety or Depression. See Table 3: all $P$-values for A-B comparisons $>0.05$ and $P$-value for $\mathrm{T}_{12}-\mathrm{T}_{0}$ compared mean change between groups $\mathrm{A}$ and $\mathrm{B}$ taken from repeated measures ANOVA after adjustment for age and gender. On average, the group recording less often (group B) tended to score lower on the PAID and both HADS scales. At $\mathrm{T}_{12}$, group $\mathrm{B}$ scored more noticeably lower than group A on the HADS anxiety subscale than at $\mathrm{T}_{0}$, but not significantly so (A: 6.8 (4.1) vs B: 4.7 (3.4); $P=0.068$ ).

The trend between $T_{0}$ and $T_{12}$ was downwards for change in mean blood glucose level and all survey scales, both in participants who recorded their blood glucose less than three times per day, and in those who recorded three or more times. The changes were not significantly different between groups A and B (all $P>0.05$ ).

The self-reported incidence of hypoglycaemic events was obtained as part of the background data because of the increased risk of hypoglycaemia in the quest to maintain HbA1c between 6 and 7.5 per cent. For the participant group as a whole (i.e., those of the original 64 with the relevant data, $n=63$ ) there was an average decrease in the incidence of hypoglycaemic events of 0.6 , which is borderline significant $(P$-value $=0.086$ from a Wilcoxon paired samples test). Baseline HbA1c was stratified by tertiles (thirds) andnumbers of hypos at $T_{0}$ and $T_{12}$ were compared across these groups. Tertile cut offs were: Group $1 \leq 7.7$, group $2>7.7$ - 8.5, and group 
Table 2. $\mathrm{T}_{0}$ and $\mathrm{T}_{12}$ comparisons: Mean (SD) for HbA1c, anxiety, depression, PAID scales and covariate data $(\mathrm{N}=64)$.

\begin{tabular}{cccccc}
\hline Variables & $\mathrm{T}_{0}$ & $\mathrm{~T}_{12}$ & $\mathrm{~T}_{12}-\mathrm{T}_{0}$ & P-value & Proportion (95\% CI $^{*}$ \\
\hline HbA1c & $8.3(1.3)$ & $8.1(1.1)$ & $-0.2(0.9)$ & 0.0536 & $0.69(0.56-0.79)^{\dagger}$ \\
Anxiety & $6.0(3.7)$ & $5.3(3.7)$ & $-0.6(2.7)$ & 0.0605 & $0.69(0.56-0.79)^{\dagger}$ \\
Depression & $4.4(3.7)$ & $3.1(3.2)$ & $-1.3(3.2)$ & 0.0015 & $0.78(0.66-0.87)^{\dagger}$ \\
PAID & $28.3(18.0)$ & $19.7(16.2)$ & $-8.6(15.5)$ & $<0.0001$ & $0.78(0.66-0.87)^{\dagger}$ \\
BMI & $26.9(5.8)$ & $27.0(5.4)$ & $0.01(1.4)$ & 0.937 & \\
Cholesterol & $4.6(1.0)$ & $4.5(0.7)$ & $-0.2(0.8)$ & 0.126 & \\
HDL & $1.7(0.7)$ & $1.7(0.5)$ & $-0.1(0.5)$ & 0.257 & \\
Triglycerides & $1.0(0.7)$ & $0.9(0.6)$ & $-0.1(0.7)$ & 0.285 & \\
Creatinine & $81.5(19.5)$ & $79.5(20.8)$ & $-3.3(20.5)$ & 0.235 & \\
SBP & $124(14.3)$ & $125(16.1)$ & $1.1(14.8)$ & 0.573 & \\
DBP & $73.3(10.7)$ & $72.8(8.5)$ & $-0.7(9.8)$ & 0.560 & \\
\hline
\end{tabular}

Key: "Proportion with $\mathrm{T}_{12}$ value at or below $\mathrm{T}_{0}$ value. ${ }^{\dagger}$ Correlation coefficient between $\mathrm{T}_{0}$ and $\mathrm{T}_{12}$ responses $P \leq 0.0001$.

Table 3. Scale Means (SD) at $\mathrm{T}_{0}$ and $\mathrm{T}_{12}$ for Groups A and B.

\begin{tabular}{cccccccc}
\hline & \multicolumn{2}{c}{$\mathrm{T}_{0}$} & \multicolumn{2}{c}{$\mathrm{T}_{12}$} & \multicolumn{2}{c}{$\mathrm{T}_{12}-\mathrm{T}_{0}$} & \multirow{2}{*}{$P$-value $\mathrm{T}_{12}-\mathrm{T}_{0}$} \\
\cline { 1 - 5 } & $\mathrm{A}$ & $\mathrm{B}$ & $\mathrm{A}$ & $\mathrm{B}$ & $\mathrm{A}$ & $\mathrm{B}$ & 0.394 \\
HbA & $8.2(1.4)$ & $8.4(1.2)$ & $8.1(1.4)$ & $8.1(1.0)$ & $-0.1(0.7)$ & $-0.3(1.0)$ & 0.372 \\
Anxiety & $7.0(4.4)$ & $5.6(3.5)$ & $6.8(4.1)$ & $4.7(3.4)$ & $-0.2(2.5)$ & $-0.9(2.8)$ & 0.749 \\
Depression & $5.4(3.8)$ & $3.9(3.7)$ & $3.6(3.4)$ & $2.8(3.2)$ & $-1.8(2.5)$ & $-1.1(3.6)$ & 0.578 \\
PAID & $32.8(21.5)$ & $26.6(16.4)$ & $22.8(19.8)$ & $18.5(14.8)$ & $-10.0(17.4)$ & $-8.1(14.8)$ & \\
\hline
\end{tabular}

Key: Group A: monitor $\geq 3$ times/ day, Group B: $<3$ per day. $P$-value $=0.068$ for t-test between groups A and B, with response square root transformed. $P$-value for $\mathrm{T}_{12}-\mathrm{T}_{0}$ compares mean change over the study between groups $\mathrm{A}$ and $\mathrm{B}$, taken from repeated measures ANOVA after adjustment for age and gender.

$3>$ 8.5. See Table 4. There was an extreme outlier in the lowest HbA1c tertile, with 22 as the number of hypos at $\mathrm{T}_{0}$ and two at $\mathrm{T}_{12}$. Data for this participant were excluded from the revised group analysis in next paragraph.

The revised group $(\mathrm{n}=62)$ had a mean $(\mathrm{SD})$ decrease in the incidence of hypos of $0.3(1.5)$, which was not significant $(P$-value $=0.131)$. See Table 4 . The majority of participants $(75 \%)$ were in fact stable with no hypos at either time point, particularly for the middle HbA1c tertile, in which $85 \%$ of participants reported no hypos at both $\mathrm{T}_{0}$ and $\mathrm{T}_{12}$. The incidence of hypos at $\mathrm{T}_{0}$ was greatest in the low and high HbA1c tertiles (mean 0.8 and 0.9 respectively). At $\mathrm{T}_{12}$ the incidence of hypos was greatest in the low HbA1c tertile. The greatest change in incidence was in the high HbA1c tertile, with a mean decrease of 0.8 . The change in incidence was not statistically significant within tertiles ( $P=0.752,1,0.074$ respectively), although the result for the high HbA1c tertile group was borderline significant. Participants in the highest HbA1c tertile, group 3 for whom the intervention was most needed, had the greatest tendency to reduce the number of hypoglycaemic events. See Table 5 for the change percentages.

\subsection{Interview Result}

Analysis of the interview data suggested that participants had undertaken a journey or process that ultimately improved their quality of life. Whilst the stages of the journey were iterative, they appeared to start in the group sessions in the first week. Participants spoke of experimenting with foods, exercise, and insulin; gaining knowledge; learning individual insulin requirements; increasing awareness of blood glucose (BG) level; gaining confidence and improving their quality of life. Participants described how they disliked having diabetes and that prior to undertaking the DAFNE course their quality of life was low. One participant described how she frequently cried about her diabetes and the restrictions it made on her life pre-DAFNE, and that she had not cried once about her diabetes since doing the course. Consequently, the first stage of the journey in improving their quality of life involved the getting of knowledge and understanding of diabetes in relation to food and insulin. The second stage was tailoring the insulin to their food intake. Rather than "feeding their insulin" they learnt how to measure the carbohydrate (CHO) content of food and match this with an appropriate insulin dose. As a 
Table 4. Mean (SD) for hypoglycaemic incidence at $\mathrm{T}_{0}$ and $\mathrm{T}_{12}$, by HbA1c tertiles.

\begin{tabular}{cccccccc}
\hline Group & $\mathrm{T}_{0}$ HbA1c & $\mathrm{T}_{12}$ HbA1c & $P$-value & $\mathrm{T}_{0}$ Hypo Incidence & $\mathrm{T}_{12}$ Hypo Incidence & Change in Incidence & $P$-value\# \\
\hline All (n= 62) & $8.3(1.3)$ & $8.1(1.1)$ & & $0.65(1.6)$ & $0.35(1.3)$ & $-0.29(1.5)$ & 0.131 \\
Tertile 1 & $7.1(0.5)$ & $7.1(0.5)$ & 0.955 & $0.8(1.8)$ & $0.6(1.5)$ & $-0.2(1.9)$ & 0.752 \\
Tertile 2 & $8.2(0.2)$ & $8.1(0.9)$ & 0.747 & $0.4(1.4)$ & $0.4(1.7)$ & $0.05(0.7)$ & 1 \\
Tertile 3 & $9.8(1.1)$ & $9.0(1.1)$ & 0.003 & $0.9(1.7)$ & $0.1(0.3)$ & $-0.8(1.7)$ & 0.074 \\
\hline
\end{tabular}

Key: \# within group $P$-value comparison for incidence of hypos between $\mathrm{T}_{0}$ and $\mathrm{T}_{12}$.

Table 5. Hypoglycaemic event profile of participants classified by HbA1c tertile.

\begin{tabular}{cccc}
\hline HbA1c Tertile & \% Stable & \% Increased & \% Decreased \\
\hline 1$) \leq 7.7$ & $71 \%$ & $10 \%$ & $19 \%$ \\
$2)>7.7-8.5$ & $85 \%$ & $10 \%$ & $5 \%$ \\
$3)>8.5$ & $70 \%$ & $5 \%$ & $25 \%$ \\
\hline
\end{tabular}

result, all participants referred to a reduction in insulin requirement leading to increasing awareness of BG level—-the third stage. Here, participants spoke about their increased awareness and ability to identify a hypoglycaemic episode at a higher BG level than previously, i.e. 3.5 instead of $2.5 \mathrm{mmol} / \mathrm{L}$. They started to realize that insulin-to-carbohydrate ratios may differ at different times of the day, and for premenopausal females, that insulin-to-CHO ratios (ICR) differed in relation to their menstrual cycle.

The fourth stage could be described as the gaining of confidence which arose from the experiential component of the 1-week part of the DAFNE program. Participants started to trust their own ability. They spoke about being able to eat when they wanted to, about feeling safe and more in control of their diabetes. They also spoke of their increased self-management confidence.

In the fifth stage, participants referred to experimenting with previous self-imposed diabetic lifestyle restriction. Some participants tried different foods; others changed the type of alcohol they drank. Also, the fear of "a hypo" (hypoglycaemic episode) no longer restricted individuals from exercising and one was able to change to a high endurance sport. Previous perceived risks associated with travel were also reduced for some. Consequently, by experimenting with those areas of their life that they felt could be improved, the participants felt they had an improved quality of life.

Whilst the first five stages of their DAFNE journey started in the first week, consolidation leading to the sixth stage followed over an extended period. The sixth stage could be described as more focused on quality of life. Participants described how they had greater enjoyment and fun and improved health. This involved not only food and drink, but greater ability to socialise, improved interpersonal relationships, closer family intimacy and greater capacity in exercise and sporting events. Improved physical and psychological health was perceived to be a direct result of the improved metabolic control. Improved metabolic control was also thought to have contributed to conception for one participant. It stands to reason that if people feel "in control" of their life that they have more control over the management of their condition, that their quality of life would be enhanced.

In summary, whilst there was no significant difference to the end of year anxiety scores, depression scores had significantly improved. Similarly, participants' diabetes-specific emotional distress scores had significantly improved. This latter finding was consistent with the qualitative data findings. Importantly, there was insufficient evidence to conclude that frequency of monitoring influenced metabolic control.

\section{Discussion}

The primary aim of the DAFNE course is to improve glycaemic control without increasing hypoglycaemic episodes juxtaposed with facilitating greater dietary freedom in eating patterns [34] [35]. A significant reduction in hypoglycaemic events was not achieved for the DAFNE program graduates in this study. However, a quarter of those in the highest HbA1c tertile group, the subgroup for whom the DAFNE strategy offered the most promise, had fewer hypoglycaemic episodes. Importantly also, in this current study, $19 \%$ of the more vulnerable lowest tertile HbA1c participants still had fewer hypoglycaemic events whilst maintaining the recommended HbA1c level. These results are consistent with Keen et al. [26]. In their study, only the highest ( $>9.6 \%)$ of five HbA1c subgroup achieved a significant improvement. 
Encouragingly, three-quarters of the sample scored at or below their initial scores for depression and for PAID - their perception of diabetes as a problem. Since the extent of people with diabetes who require psychological support warrants targeted interventions which may ultimately improve metabolic outcomes [36]-[38] and quality of life [36] [39], a DAFNE-type intervention should be considered. Although the diabetes-depression link remains dubious [40], the prevalence of anxiety and depression in a large United Kingdom study [41] "...suggest that there is an increased prevalence of clinically relevant anxiety in females and of depression in males with type 1 diabetes when compared with the normative data.” This study did not explore gender differences.

Whilst this study also sought to explore the impact of frequency of monitoring on glycaemic control, no significant difference was found in the two groups. That is, regardless of the frequency of SMBG, both groups had similar scores for HbA1c, levels of anxiety and depression, as well as their perceptions of diabetes and problem areas.

Consistent with this finding, the interview data in this study reflected a more positive outlook post-DAFNE. Possibly contributing to the perceived improvement in blood glucose control for these DAFNE graduates is the apparent increased awareness and ability to identify hypoglycaemia at a higher BG level than previously. Improved hypoglycaemia awareness enabling early correction reported by some interviewees two years or more after completing the DAFNE course is important for metabolic control and a sense of control over life in general. Interventions such as DAFNE, which focus on changing detrimental behaviours, may be useful to restore hypoglycaemic awareness and protection from severe hypoglycaemia [42].

Nevertheless, two main limitations need to be acknowledged. As a continuous quality-assurance project in one hospital's diabetes centre, the study did not have a control group and cannot draw conclusions about the separate effect of the expertise of DAFNE-certified staff, the educational content, or strategies such as the vicarious sharing of experiences between six-to-eight participants. Second, this study did not collect or have access to data on DAFNE graduates' degree of confidence with BG level interpretation to identify patterns, or on their education level. The DAFNE educators in this diabetes centre found that some graduates need on-going education and support with interpreting records and identifying BGL patterns.

Further research is needed to focus on interpretation of BG level patterns and to explore why this aspect of diabetes self-management is so challenging for people living with type 1 diabetes. Also, does the reduction in hypoglycaemic events occur more in first six months after the week-long DAFNE course, or is the reduction more gradual as suggested by Speight et al. [10]? For example, the incidence of hypoglycaemic events by HbA1c level and frequency of monitoring as participants progressed through the stages of behaviour change and "learn" how to apply the DAFNE principles could be of interest. An understanding of the time frame and process from learning to implementation is necessary for diabetes educators when guiding the expectations of future DAFNE course participants.

\section{Conclusion}

Consistent with others, this study found an improved perspective on diabetes management two years postDAFNE. In addition, while the study did not find a significant difference in hypoglycaemic episodes between one group who recorded less than the recommended times, compared to another that did, the reduction in hyperglycaemic events for the higher tertile HbA1c group suggests more detailed research is needed. Newer meter technologies may support such research. Today there are blood glucose meters that have the capacity to enter ICR, insulin sensitivity factor (ISF), blood glucose targets, and duration of insulin action. Thus when blood glucose is tested, the meter uses such parameters to calculate a recommended insulin dose. The meter stores the glucose measurement, carbohydrate consumed and insulin dose administered. Hence data are used to continually evaluate the ratios to bring the BG back to target. Technology cannot, however, replace the individual's need to interpret the extra information to make informed decisions about the insulin dose. The individual's responsibility for diabetes management may not change but the way in which data are displayed, stored and used has and will change. Concomitantly however, the individual's perception about their ability to manage their diabetes remains paramount if their metabolic control and quality of life is to be improved. A DAFNE-type course remains relevant.

\section{Acknowledgements}

The study was funded by the Nurses Memorial Centre Trust of Western Australia. The authors wish to ac- 
knowledge the invaluable help from data entry staff and outpatients who participated.

\section{References}

[1] Anderson, R., Funnell, M., Butler, P., Arnold, M., Fitzgerald, J. and Feste, C. (1995) Patient Empowerment. Results of a Randomized Controlled Trial. Diabetes Care, 18, 943-949.

[2] Colagiuri, S., Brnabic, A., Gomez, M., Fitzgerald, B., Buckley, A. and Colagiuri, R. (2009) Diabco\$t Australia Type 1: Assessing the Burden of Type 1 Diabetes in Australia. Diabetes Australia, Canberra, 1-27.

[3] Moss, S., Klein, R. and Klein, B. (1999) Risk Factors for Hospitalisation in People with Diabetes. Archives of Internal Medicine, 159, 2053-2057. http://dx.doi.org/10.1001/archinte.159.17.2053

[4] Rutten, G. (2005) Diabetes Patient Education: Time for a New Era. Diabetic Medicine, 22, 671-673. http://dx.doi.org/10.1111/j.1464-5491.2005.01497.x

[5] Krichbaum, K., Aarestad, V. and Buethe, M. (2003) Exploring the Connection between Self-Efficacy and Effective Diabetes Self-Management. The Diabetes Educator, 29, 653-662. http://dx.doi.org/10.1177/014572170302900411

[6] Lowe, J., Linjawi, S., Mensch, M., James, K. and Attia, J. (2008) Flexible Eating and Flexible Insulin Dosing in Patients with Diabetes: Results of an Intensive Self-Management Course. Diabetes Research and Clinical Practice, 80, 439-443. http://dx.doi.org/10.1016/j.diabres.2008.02.003

[7] Glasgow, R. (1999) Outcomes of and for Diabetes Education Research. The Diabetes Educator, 25, 74-88. http://dx.doi.org/10.1177/014572179902500625

[8] Shearer, A., Bagust, A., Sanderson, D., Heller, S. and Roberts, S. (2004) Cost-Effectiveness of Flexible Intensive Insulin Management to Enable Dietary Freedom in People with Type 1 Diabetes in the UK. Diabetic Medicine: A Journal of the British Diabetic Association, 21, 460-467. http://qelibresources.health.wa.gov.au/login?url=http://search.ebscohost.com/login.aspx?direct=true\&db=mnh\&AN=1 5089791\&site=ehost-live\&scope $=$ site

[9] DAFNE Study Group (2002) Training in Flexible, Intensive Insulin Management to Enable Dietary Freedom in People with Type 1 Diabetes: Dose Adjustment for Normal Eating (DAFNE) Randomised Controlled Trial. British Medical Journal, 325, 746-751. http://dx.doi.org/10.1136/bmj.325.7367.746

[10] Speight, J., Amiel, S.A., Bradley, C., et al. (2010) Long-Term Biomedical and Psychosocial Outcomes Following DAFNE (Dose Adjustment for Normal Eating) Structured Education to Promote Intensive Insulin Therapy in Adults with Sub-Optimally Controlled Type 1 Diabetes. Diabetes Research and Clinical Practice, 89, 22-29. http://dx.doi.org/10.1016/j.diabres.2010.03.017

[11] Samann, A., Muhlhauser, I., Bender, R., Kloos, C. and Muller, U.A. (2005) Glycaemic Control and Severe Hypoglycaemia Following Training in Flexible, Intensive Insulin Therapy to Enable Dietary Freedom in People with Type 1 Diabetes: A Prospective Implementation Study. Diabetologia, 48, 1965-1970. http://dx.doi.org/10.1007/s00125-005-1905-1

[12] Speight, J., Conn, J., Dunning, T. and Skinner, T.C. (2012) Diabetes Australia Position Statement. A New Language for Diabetes: Improving Communications with and about People with Diabetes. Diabetes Research and Clinical Practice, 97, 425-431. http://dx.doi.org/10.1016/j.diabres.2012.03.015

[13] Siminerio, L., Piatt, G. and Zgibor, J. (2005) Implementing the Chronic Care Model for Improvements in Diabetes Care and Education in a Rural Primary Care Practice. The Diabetes Educator, 31, 225-234. http://dx.doi.org/10.1177/0145721705275325

[14] Welch, G., Rose, G. and Ernst, D. (2006) Motivational Interviewing and Diabetes: What Is It, How Is It Used, and Does It Work? Diabetes Spectrum, 19, 5-11. http://dx.doi.org/10.2337/diaspect.19.1.5

[15] Bandura, A. (1997) Self-Efficacy: The Exercise of Control. W. H. Freeman and Company, New York.

[16] Bandura, A. (2004) Health Promotion by Social Cognitive Means. Health Education \& Behavior, 31, 143-164. http://dx.doi.org/10.1177/1090198104263660

[17] Montgomery, B. (2008) Helping People Live with Diabetes: The Keys to Successful Behaviour Change. Australian Diabetes Educator, 11, 11-12, 14.

[18] Shannon, B., Bagby, R., Wang, M.Q. and Trenker, L. (1990) Self-Efficacy: A Contributor to the Explanation of Eating Behavior. Health Education Research, 5, 395-407. http://dx.doi.org/10.1093/her/5.4.395

[19] Skinner, T. (2006) What Does Make the Difference? Diabetic Medicine, 23, 933-934. http://dx.doi.org/10.1111/j.1464-5491.2006.01908.x

[20] Miller, K., Beck, R., Bergenstal, R., Goland, R.S., Haller, M.J., McGill, J.B., et al. (2013) Evidence of a Strong Association between Frequency of Self-Monitoring of Blood Glucose and Hemoglobin $\mathrm{A}_{1 \mathrm{c}}$ Levels in $\mathrm{T}_{1 \mathrm{~d}}$ Exchange Clinic Registry Participants. Diabetes Care, 36, 2009-2014. http://dx.doi.org/10.2337/dc12-1770 
[21] Piette, J. and Glasgow, R. (2001) Education and Home Glucose Monitoring. In: Gerstein, H. and Haynes, R., Eds., Evidence Based Diabetes Care, BC Decker, Hamilton/London, 207-251.

[22] Kolb, H., Kempf, K., Martin, S., Stumvoll, M. and Landgraf, R. (2010) On What Evidence-Base Do We Recommend Self-Monitoring of Blood Glucose? Diabetes Research and Clinical Practice, 87, 150-156. http://www.sciencedirect.com/science/article/B6T5Y-4XR5W11-2/2/f99583b836338a09eae4aa9969020e38 http://dx.doi.org/10.1016/j.diabres.2009.10.014

[23] Ingadottir, B. and Halldorsdottir, S. (2008) To Discipline a "Dog”: The Essential Structure of Mastering Diabetes. Qualitative Health Research, 18, 606-619. http://dx.doi.org/10.1177/1049732308316346

[24] Fisher, E.B., Thorpe, C.T., DeVellis, B.M. and DeVellis, R.F. (2007) Healthy Coping, Negative Emotions, and Diabetes Management. The Diabetes Educator, 33, 1080-1103. http://dx.doi.org/10.1177/0145721707309808

[25] Hopkins, D., Lawrence, I., Mansell, P., Thompson, G., Amiel, S. and Heller, S. (2008) DAFNE (Dose Adjustment for Normal Eating) Training Delivered in Routine Clinical Practice Is Associated with Significant Improvements in Measure of Quality of Life and Psychological Distress. Diabetic Medicine, 25, 16.

[26] Keen, A., Duncan, E., McKillop-Smith, A., Evans, N. and Gold, A. (2012) Dose Adjustment for Normal Eating (DAFNE) in Routine Clinical Practice: Who Benefit? Diabetic Medicine, 29, 670-676. http://dx.doi.org/10.1111/j.1464-5491.2011.03479.x

[27] McIntyre, D. (2006) DAFNE (Dose Adjustment for Normal Eating): Structured Education in Insulin Replacement Therapy for Type 1 Diabetes. Medical Journal of Australia, 184, 317-318.

[28] Evans, J.M.M., Newton, R.W., Ruta, D.A., MacDonald, T.M., Stevenson, R.J. and Morris, A.D. (1999) Frequency of Blood Glucose Monitoring in Relation to Glycaemic Control: Observational Study with Diabetes Database. British Medical Journal, 319, 83-86. http://dx.doi.org/10.1136/bmj.319.7202.83

[29] Zigmond, A. and Snaith, R. (1983) The Hospital Anxiety and Depression Scale. Acta Psychiatrica Scandinavica, 67, 361-370. http://dx.doi.org/10.1111/j.1600-0447.1983.tb09716.x

[30] Polonsky, W., Anderson, B., Lohrer, P., Welch, G., Jacobson, A.M., Aponte, J.E. and Schwartz, C.E. (1995) Assessment of Diabetes-Related Distress. Diabetes Care, 18, 754-760. http://dx.doi.org/10.2337/diacare.18.6.754

[31] R Core Team (2013) R: A Language and Environment for Statistical Computing. R Foundation for Statistical Computing, Vienna, 2238.

[32] Faul, F., Erdfelder, E., Lang, A.G. and Buchner, A. (2007) G*Power 3: A Flexible Statistical Power Analysis Program for the Social, Behavioral, and Biomedical Sciences. Behavior Research Methods, 39, 175-191. http://dx.doi.org/10.3758/BF03193146

[33] Welch, G., Weinger, K., Anderson, B. and Polonsky, W. (2003) Responsiveness of the Problem Areas in Diabetes (PAID) Questionnaire. Diabetic Medicine, 20, 69-72. http://dx.doi.org/10.1046/j.1464-5491.2003.00832.x

[34] Oliver, L., Thompson, G. and on Behalf of the DAFNE Programme (2009) The DAFNE Collaborative. Experiences of Developing a Nationally Delivered Evidence-Based, Quality-Assured Programme for People with Type 1 Diabetes. Practical Diabetes International, 26, 371-377. http://dx.doi.org/10.1002/pdi.1424

[35] Papanas, N. and Maltezos, E. (2008) Education for Dietary Freedom in Type 1 Diabetes? Yes, It’s Possible. The Diabetes Educator, 34, 54-58. http://dx.doi.org/10.1177/0145721707312464

[36] Egede, L.E. and Ellis, C. (2010) Diabetes and Depression: Global Perspectives. Diabetes Research and Clinical Practice, 87, 302-312. http://dx.doi.org/10.1016/j.diabres.2010.01.024

[37] Grigsby, A.B., Anderson, R.J., Freedland, K.E., Clouse, R.E. and Lustman, P.J. (2002) Prevalence of Anxiety in Adults with Diabetes: A Systematic Review. Journal of Psychosomatic Research, 53, 1053-1060. http://dx.doi.org/10.1016/S0022-3999(02)00417-8

[38] Lloyd, C., Dyert, P. and Barnett, A. (2002) Prevalence of Symptoms of Depression and Anxiety in a Diabetes Clinic Population. Diabetic Medicine, 17, 198-202. http://dx.doi.org/10.1046/j.1464-5491.2000.00260.x

[39] Goldney, R., Phillips, P., Fisher, L. and Wilson, D. (2004) Diabetes, Depression, and Quality of Life. Diabetes Care, 27, 1066-1070. http://dx.doi.org/10.2337/diacare.27.5.1066

[40] Barnard, K., Skinner, T. and Peveler, R. (2006) The Prevalence of Co-Morbid Depression in Adults with Type 1 Diabetes: Systematic Literature Review. Diabetic Medicine, 23, 445-448. http://dx.doi.org/10.1111/j.1464-5491.2006.01814.x

[41] Shaban, M.C., Fosbury, J., Kerr, D. and Cavan, D.A. (2006) The Prevalence of Depression and Anxiety in Adults with Type 1 Diabetes. Diabetic Medicine, 23, 1381-1384. http://dx.doi.org/10.1111/j.1464-5491.2006.02012.x

[42] Smith, C.B., Choudhary, P., Pernet, A., Hopkins, D. and Amiel, S.A. (2009) Hypoglycemia Unawareness Is Associated with Reduced Adherence to Therapeutic Decisions in Patients with Type 1 Diabetes: Evidence from a Clinical Audit. Diabetes Care, 32, 1196-1198. http://dx.doi.org/10.2337/dc08-2259 
Scientific Research Publishing (SCIRP) is one of the largest Open Access journal publishers. It is currently publishing more than 200 open access, online, peer-reviewed journals covering a wide range of academic disciplines. SCIRP serves the worldwide academic communities and contributes to the progress and application of science with its publication.

Other selected journals from SCIRP are listed as below. Submit your manuscript to us via either submit@scirp.org or Online Submission Portal.
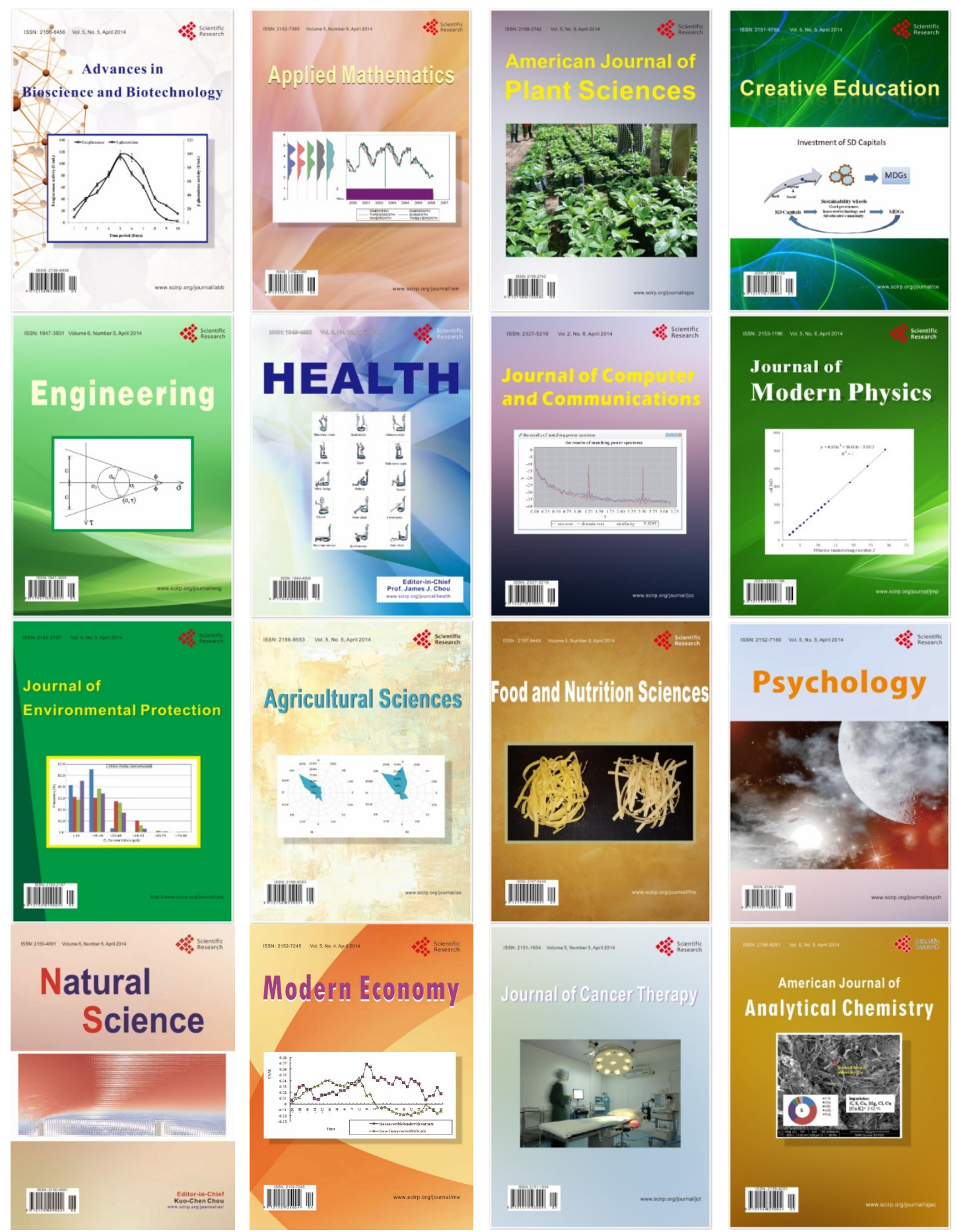